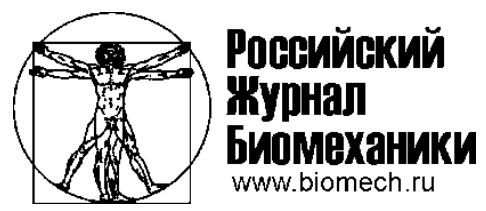

\title{
НОВЫЙ ПОДХОД К ОПРЕДЕЛЕНИЮ ПОНЯТИЯ И ВЫЯВЛЕНИЮ «МЕРТВОЙ ЗОНЫ» В ЖИМЕ ШТАНГИ ЛЕЖА
}

\author{
Г.А. Самсонов
}

Национальный государственный университет физической культуры, спорта и здоровья имени П.Ф. Лесгафта, Россия, 190121, Санкт-Петербург, ул. Декабристов, 35, e-mail: spb_biomechanics@rambler.ru

\begin{abstract}
Аннотация. Жим штанги лежа - отдельный вид спорта, а также одно из трех соревновательных упражнений в пауэрлифтинге. При выполнении жима штанги лежа в фразе подъема штанги от груди имеет место «мертвая зона» определенный временной промежуток, на котором снижается скорость движения штанги. Имеются различия в том, как исследователи техники жима штанги лежа и тренеры выявляют «мертвую зону». Тренеры выявляют «мертвую зону» эмпирически и субъективно, а исследователи используют объективные методы. В результате возникает расхождение в понимании «мертвой зоны» тренерами и исследователями, что затрудняет использование данных научных исследований в тренировочном процессе. Цель исследования - разработка нового определения понятия «мертвая зона» в жиме штанги лежа и нового подхода к выявлению «мертвой зоны». Методы исследования: видеосъемка жима штанги лежа в сагиттальной плоскости и расчет скорости и ускорения центра тяжести штанги на основе видеоданных. Организация исследования: десять квалифицированных пауэрлифтеров (кандидатов в мастера спорта и мастеров спорта) выполняли жим штанги лежа с отягощением 100\% от максимума (одно повторение) по соревновательным правилам без экипировки. Значение 100\%-ного отягощения определялось посредством последовательного увеличения нагрузки до возникновения неудачной попытки. Отягощение, предшествовавшее неудачной попытке, считалось максимальным. Результаты исследования: понятие «мертвая зона» разделено на понятия: «мертвая зона» и «неблагоприятная зона». «Мертвая зона» - снижение скорости штанги ниже порогового значения $0,1 \mathrm{~m} / \mathrm{c}$, при достижении которого движение штанги воспринимается как слишком медленное. «Неблагоприятная зона» - участок кривой «время-сила», на котором сила, приложенная к штанге, меньше веса штанги в фразе подъема штанги от груди. Возможно наличие двух «мертвых зон» - одной в начале фазы подъема штанги и одной в конце. Также возможно наличие «неблагоприятной зоны» и отсутствие «мертвой зоны». «Неблагоприятная зона» всегда предшествует «мертвой зоне». Неудачные попытки всегда происходят в «мертвой зоне».
\end{abstract}

Ключевые слова: жим штанги лежа, пауэрлифтинг, «мертвая точка», «мертвая зона», «неблагоприятная зона».

\section{ВВЕДЕНИЕ}

Жим штанги лежа - весьма популярное силовое упражнение. Оно используется и в качестве средства силовой подготовки, и в качестве соревновательного упражнения. В настоящее время проводятся чемпионаты мира по пауэрлифтингу (жим штанги лежа - одно из упражнений пауэрлифтинга) и отдельно по жиму штанги. 
Жим штанги лежа выполняется на специальной скамье. По команде «старт» спортсмен, сгибая руки, опускает штангу на грудь (фаза опускания), после этого по команде «жим» начинает выпрямлять руки, поднимая штангу вверх (фаза подъема). Попытка считается успешной, если спортсмен смог полностью разогнуть руки в локтевых суставах. При большой массе штанги спортсмены зачастую не в состоянии выполнить подъем штанги вверх и зафиксировать руки в локтевых суставах. В этом случае попытка считается неудавшейся.

На современном этапе проводится большое количество исследований, направленных на оптимизацию технической подготовки в жиме штанги лежа. В частности, техника жима штанги лежа активно исследуется группами ученых из Норвегии [15-17], Чехии [8-10] и США [6, 11, 13]. В нашей стране данная проблема также изучается [1-5].

Особое внимание исследователей привлекает «мертвая точка» - определенный момент во время фазы подъема штанги от груди, при котором штанга как бы останавливается на определенное время, а затем продолжает движение (либо не продолжает, если вес штанги слишком велик). Интерес к этому моменту объясняется тем, что «мертвая точка» является камнем преткновения (the sticking point), и от преодоления «мертвой точки» зависит, будет попытка успешной или нет.

Проблема заключается в способе выявления самого факта наличия «мертвой точки». Большинство тренеров не использует инструментальные методики в учебнотренировочном процессе, поэтому «мертвую точку» они, как правило, определяют на глаз: когда штанга движется очень медленно или останавливается совсем. Однако возникает вопрос: «Насколько медленно должна двигаться штанга, чтобы назвать это явление “мертвой точкой”?» Другими словами: «Какие значения скорости штанги соответствуют диапазону, который тренеры считают медленным?» В каком случае тренер скажет, что «мертвая точка» имеет место, а в каком - нет? Следовательно, хотя само явление «мертвой точки» объективно, подход тренеров к ее определению достаточно субъективен.

Ученые используют несколько иные способы определения факта наличия «мертвой точки». Большинство исследователей опираются на данные N. Madsen и T. McLaughlin [12], которые предложили считать «мертвой точкой» первый локальный минимум вертикального ускорения штанги после начала фазы подъема, в который к штанге прикладывается минимум силы (точка 4, рис. 1).

Несколько позднее J.E. Lander et al. [11] предложили использовать термин «мертвая зона» (the sticking region), который описывал наличие определенного участка кривой время - сила. Начало «мертвой зоны» соответствовало моменту, в котором сила, прикладываемая атлетом к штанге, была равна силе тяжести штанги (точка 3, см. рис. 1). На кривой время - скорость эта точка соответствует первому локальному максимуму скорости центра тяжести штанги при ее движении вверх $\left(v_{\max 1}\right)$. Окончание «мертвой зоны» также соответствует моменту, в котором сила, прикладываемая атлетом к штанге, была равна силе тяжести штанги (точка 5, см. рис. 1), при этом скорость центра тяжести штанги минимальна $\left(v_{\min }\right)$. Авторы считали, что в фазе подъема штанги от груди возможно наличие только одной «мертвой зоны».

C тех пор подход к определению «мертвой зоны» среди ученых практически не изменился. Современные исследователи данной проблемы $[6,8,10,16,17]$ также считают «мертвой зоной» участок снижения силы, приложенной к штанге в фазе подъема штанги от груди.

Тем не менее у данного подхода есть ряд существенных недостатков:

1. Снижение приложенной силы не всегда соответствует достаточно значимому уменьшению скорости штанги, что приводит к противоречиям в понимании явления 


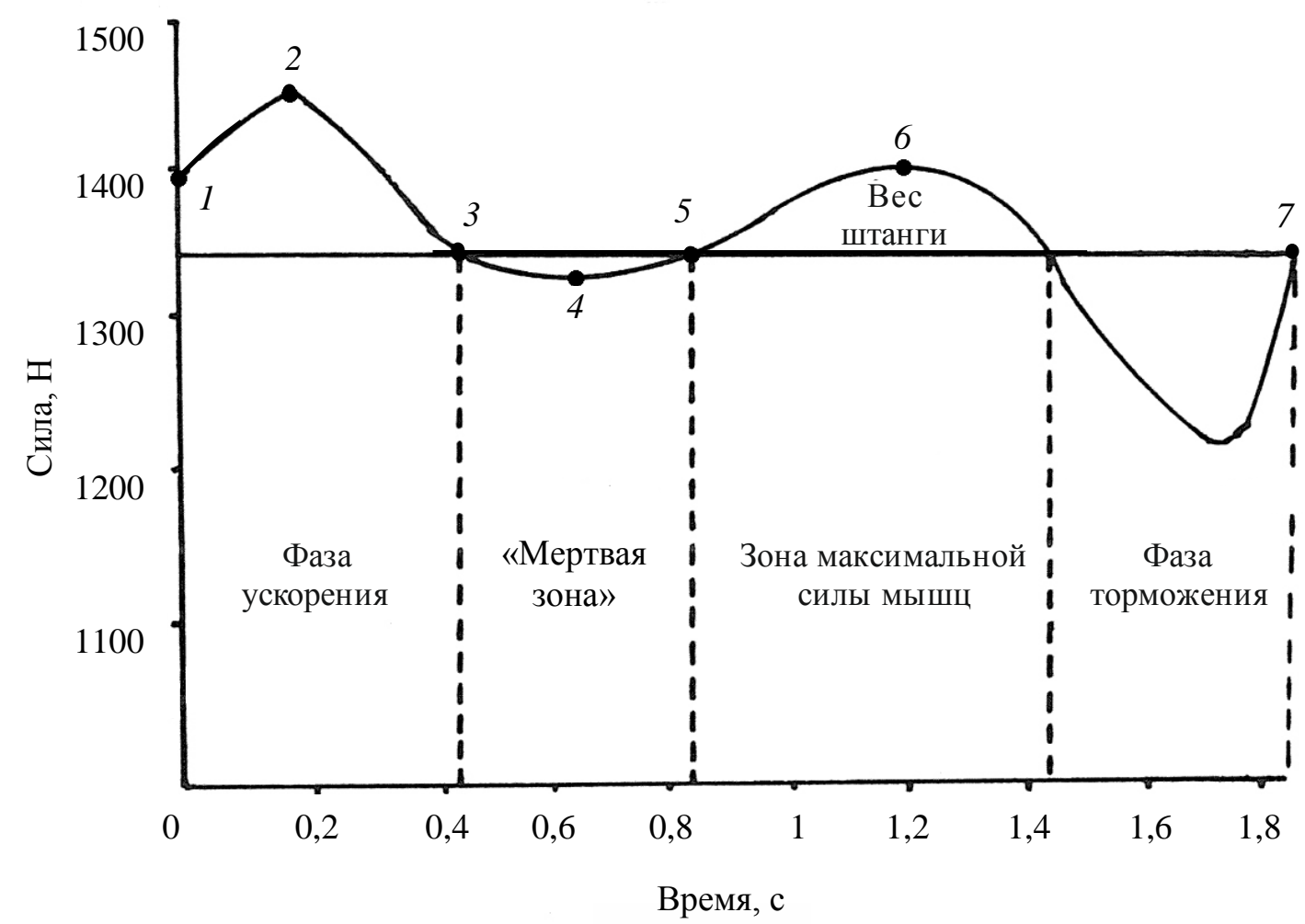

Рис. 1. Изменение вертикальной составляющей силы давления на гриф во время фазы подъема при жиме штанги с отягощением $100 \%$ от максимума [7]. Обозначение фаз дается на основе исследования J.E. Lander et al. [11]

«мертвой зоны» тренером и исследователем. Фаза, воспринимаемая ученым как «мертвая зона», может восприниматься тренером совершенно иначе. Например, если имеет место снижение скорости штанги, но штанга все равно продолжает движение с достаточно высокой скоростью, тренер не будет воспринимать это как «мертвую зону».

2. Описанное выше расхождение в понимании «мертвой зоны» тренером и исследователем обусловливает сложность сопоставления данных, полученных учеными, с эмпирическим опытом тренеров и судей. Помимо того, неясно, при каких отягощениях проявляется «мертвая зона» и какие группы спортсменов более подвержены ее влиянию (исходя из квалификации и весовой категории).

3. J.E. Lander et al. [11] предполагали, что в «мертвой зоне» наиболее вероятен отказ от выполнения движения (т.е. попытка является неудачной). Последующие исследования, основанные на разработанном J.E. Lander et al. [11] критерии «мертвой зоны», не подтвердили этого предположения. B.C. Elliot, G.J. Wilson, G. Kerr [7] показали, что только один элитный пауэрлифтер из десяти потерпел неудачу в области «мертвой зоны», все остальные участники эксперимента при выполнении жима штанги с отягощением в $104 \%$ от максимума, терпели неудачу в фазе торможения (см. рис. 1). Исследования [15] также показали, что шесть из одиннадцати начинающих спортсменов, которые преодолели «мертвую зону», все-таки потерпели неудачу в последующих фазах подъема штанги от груди. Авторы объяснили это тем, что даже если спортсмен не потерпел неудачу в «мертвой зоне», то ее наличие может рассматриваться как неблагоприятное состояние, которое накладывает ограничения на показанный спортсменом результат в жиме штанги лежа. 
Следует отметить, что у подхода J.E. Lander et al. [11] есть существенное преимущество: данный подход объективен, так как используются объективные критерии (сила, приложенная к штанге). К тому же независимо от массы атлета и его квалификации при использовании максимальных отягощений всегда сразу после начала подъема штанги ее вертикальная составляющая скорости достигает максимума $\left(v_{\max 1}\right)$, после чего начинается ее снижение.

Таким образом, ученые для выявления «мертвой зоны» в жиме штанги лежа использовали кривую время - сила. В то же время тренеры и судьи воспринимают наличие «мертвой зоны» или ее отсутствие визуально, по снижению скорости штанги. Следует помнить, что зависимость время-скорость и зависимость время - сила взаимосвязаны, так как в основе каждой из них лежат одни и те же механические закономерности, позволяющие в случае необходимости переходить от одной зависимости к другой, используя известные алгоритмы (решение прямой и обратной задач динамики). Выбор той или иной зависимости обусловливается прежде всего задачами исследования.

В связи с вышеизложенным цель настоящего исследования состояла в разработке нового определения понятия «мертвая зона» в жиме штанги лежа и нового подхода к выявлению «мертвой зоны».

В исследовании были поставлены следующие задачи:

1. Предложить объективный критерий наличия «мертвой зоны» на основе анализа кривой время - скорость центра тяжести штанги в фазе подъема штанги от груди.

2. На основе разработанного критерия установить возможность наличия нескольких «мертвых зон» в фазе подъема штанги от груди.

3. Установить характерные варианты изменения кривой время - скорость в фазе подъема штанги от груди.

\section{МАТЕРИАЛЫ И МЕТОДЫ ИССЛЕДОВАНИЯ}

В исследовании принимали участие десять квалифицированных пауэрлифтеров (кандидатов в мастера спорта и мастеров спорта). Исследуемые выполняли разминку, а затем жим штанги лежа с отягощением 100 \% от максимума (одно повторение) по соревновательным правилам, но без экипировки. Значение 100\%-ного отягощения определялось посредством последовательного увеличения нагрузки до возникновения неудачной попытки. Отягощение, предшествовавшее неудачной попытке, считалось максимальным.

В сагиттальной плоскости посредством камеры Casio Ex-F1 осуществлялась видеосъемка движений спортсмена с частотой 60 кадр./c (разрешение $1920 \times 1080$ пикселей).

Полученные видеоматериалы обрабатывались в программе PixelFarm PFTrack 2011: координаты центра тяжести штанги отслеживались в автоматическом режиме с последующим экспортом в текстовый файл. На основе полученных координат с учетом масштаба в программе Microsoft Excel 2013 рассчитывались вертикальные составляющие скорости и ускорения центра тяжести штанги по формуле, предусматривающей сглаживание по пяти точкам.

\section{РЕЗУЛЬТАТЫ И ИХ ОБСУЖДЕНИЕ}

На основе традиционного способа определения «мертвой зоны» исследователи предлагали разные варианты фазового деления жима штанги лежа, однако все они подразумевали наличие только одной «мертвой зоны». 
При анализе полученных экспериментальных данных автор столкнулся с рядом проблем, связанных с разделением фазы подъема штанги от груди на подфазы по критериям, разработанным J.E. Lander et al. [11].

Во-первых, кривая время - скорость штанги очень редко имела сходство у двух разных спортсменов. Было обнаружено, что у одних исследуемых имелся резко выраженный пик скорости в начале подъема штанги от груди, у других пик скорости штанги приходился на окончание движения. У некоторых испытуемых было обнаружено два примерно одинаковых пика скорости штанги - в начале и в конце подъема штанги от груди.

Во-вторых, у исследуемых автором атлетов явление, которое J.E. Lander et al. [11] называют «мертвой зоной», проявлялось в разных временных промежутках фазы подъема штанги от груди.

Данные одной категории исследуемых соответствовали описанию «мертвой зоны» по критериям J.E. Lander et al. [11]: после первого пика скорости в начале подъема имело место снижение вертикальной составляющей скорости, что соответствовало снижению силы, приложенной к штанге (рис. 2).

Но были также две другие категории испытуемых: у одной из них снижение вертикальной составляющей скорости штанги проявлялось в конце движения (в момент, когда атлет уже почти распрямил руки) (рис. 3). У другой категории наблюдалось два значимых снижения вертикальной составляющей скорости штанги, каждое из которых можно считать «мертвой зоной» (рис. 4).

Более того, трое испытуемых демонстрировали снижение вертикальной составляющей скорости штанги, которое тренеры не классифицировали как «мертвую зону» (рис. 5).

Чтобы избежать ситуаций, в которых исследователи наблюдают «мертвую зону», а тренеры - нет, автор предлагает ввести два понятия: «мертвая зона» и «неблагоприятная зона» (рис. 6).

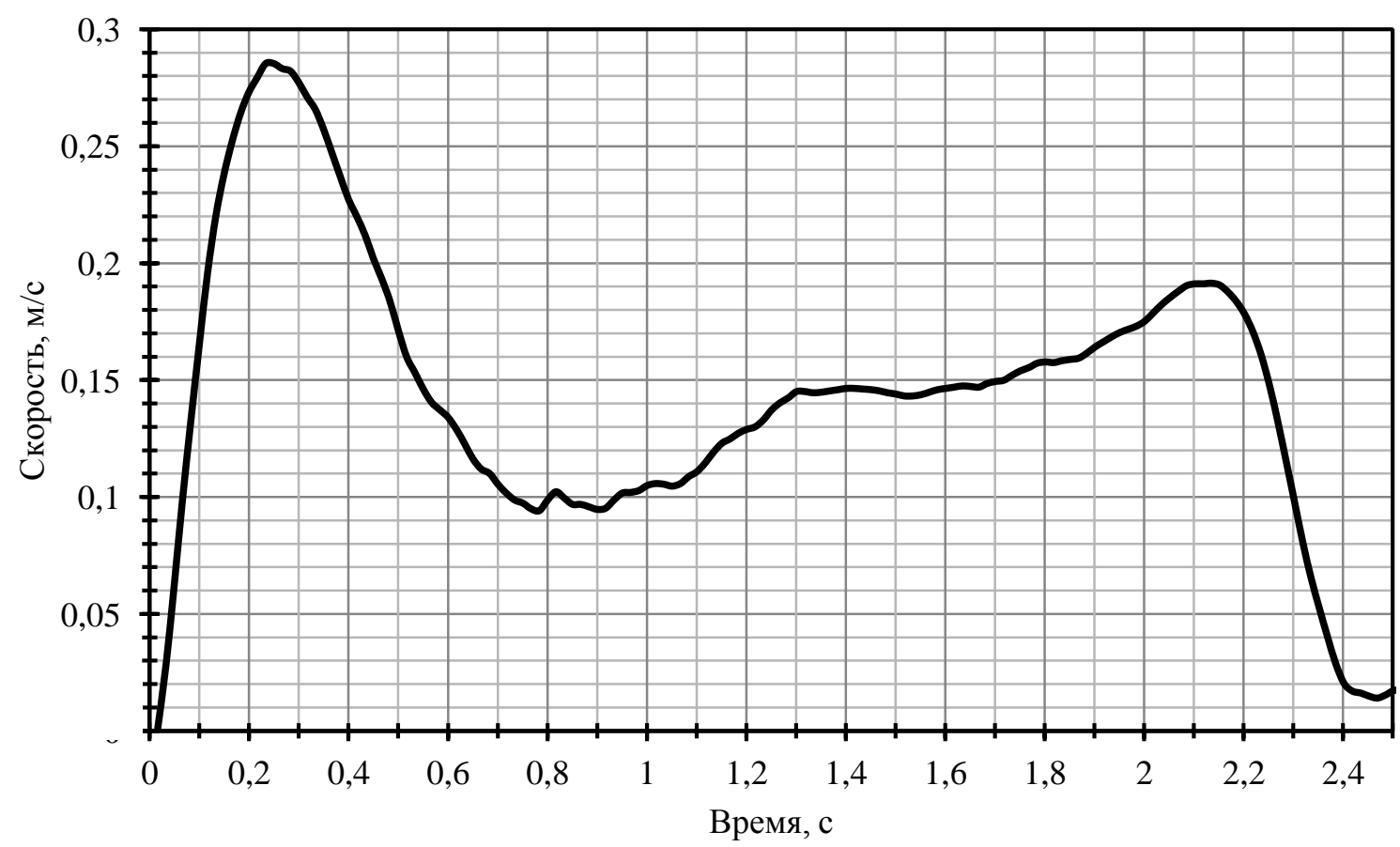

Рис. 2. Кривая время-скорость во время фазы подъема штанги от груди (исследуемый 1) 


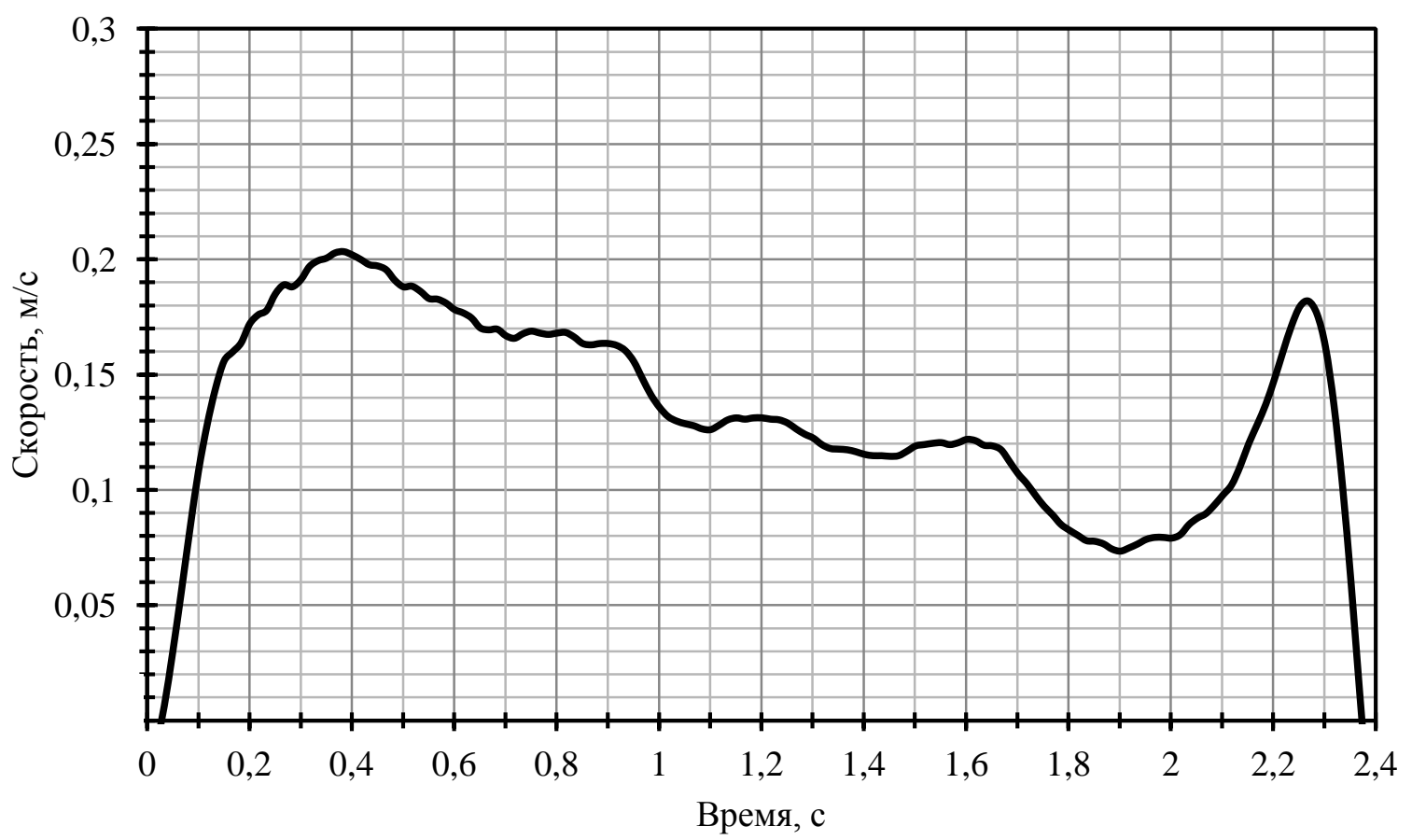

Рис. 3. Кривая время-скорость во время фазы подъема штанги от груди (исследуемый 2)

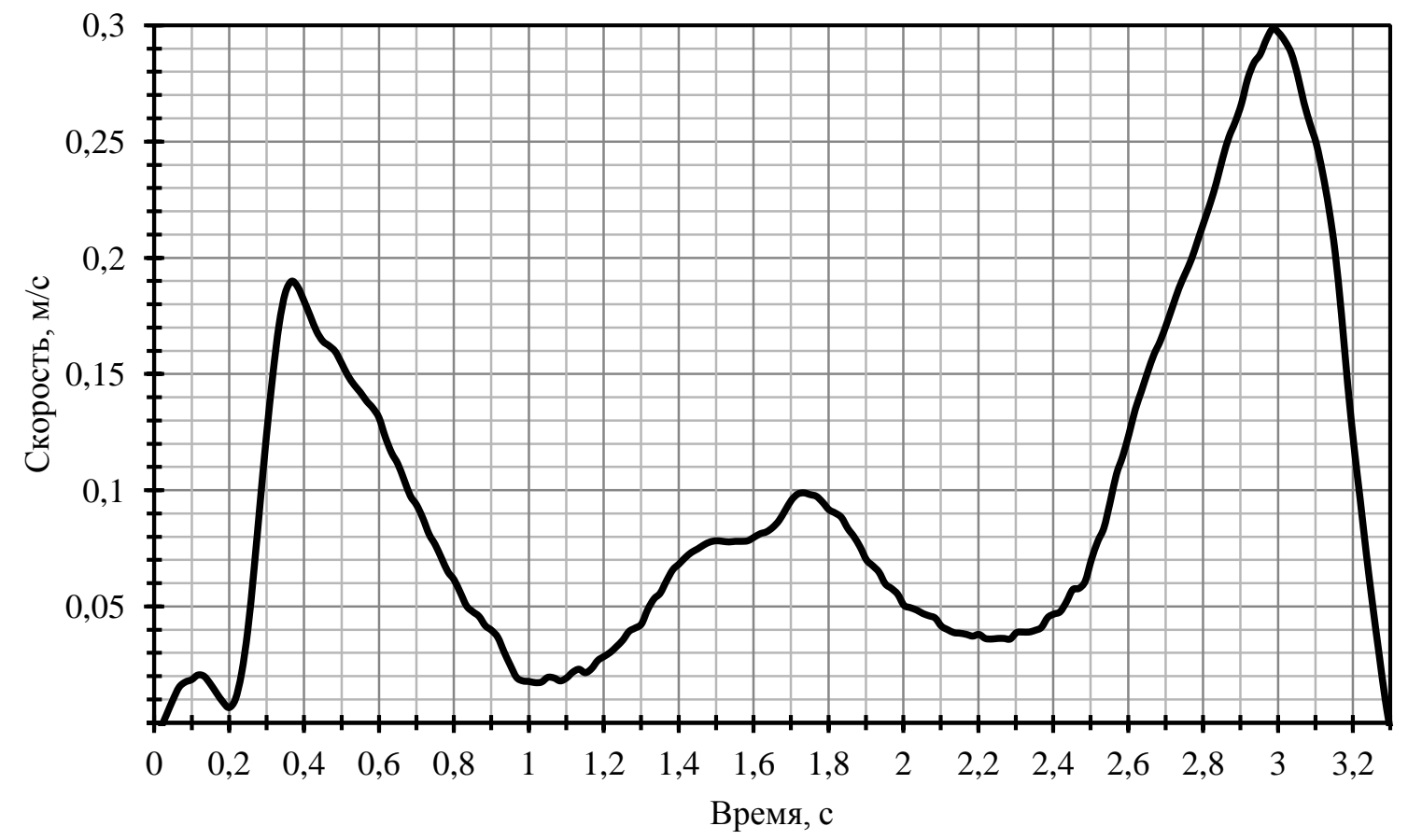

Рис. 4. Кривая время-скорость во время фазы подъема штанги от груди (исследуемый 3 )

Под термином «мертвая зона» предлагается понимать явление, наблюдаемое тренером: снижение скорости штанги ниже определенного порогового значения, при достижении которого движение штанги воспринимается как слишком медленное. 


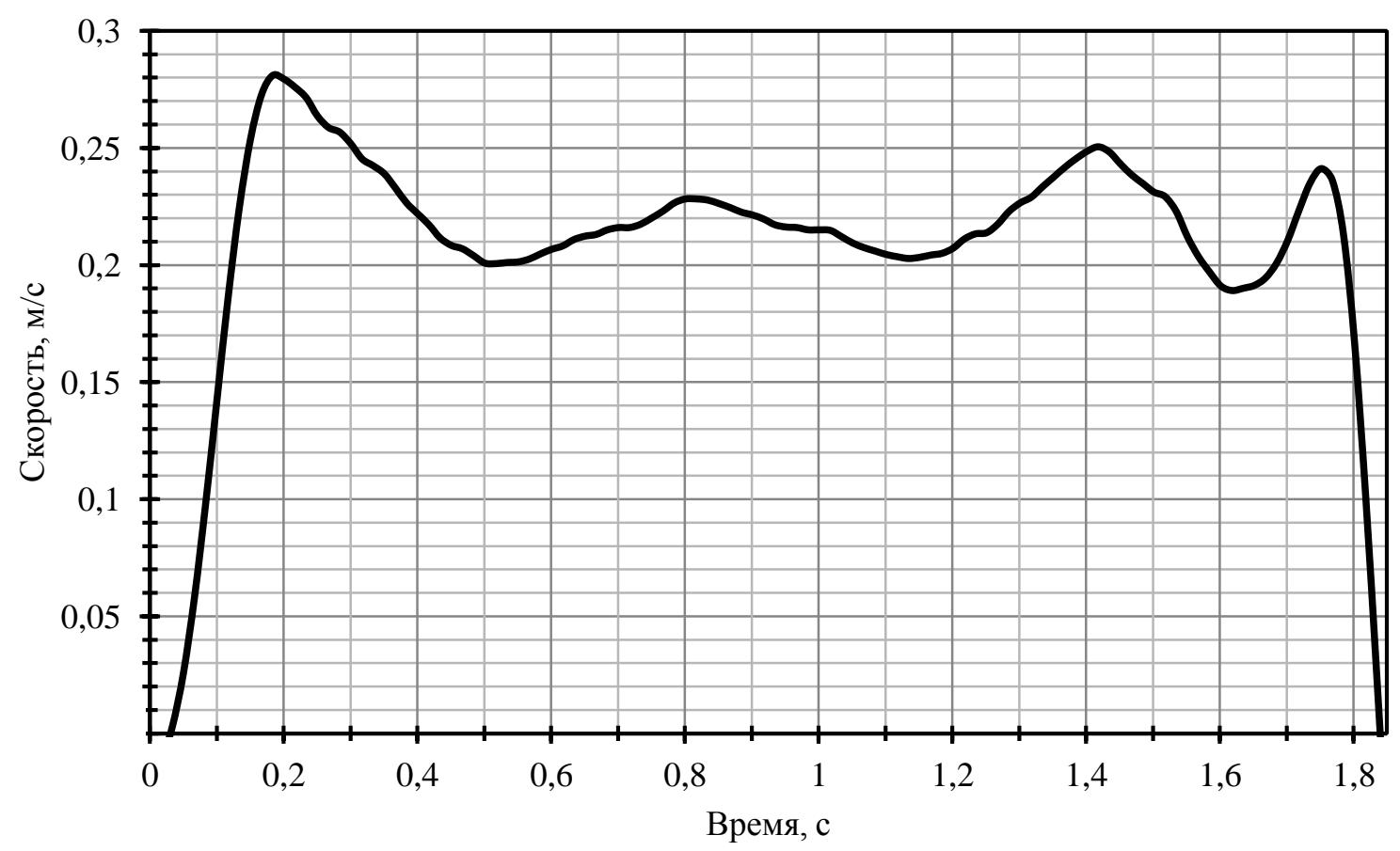

Рис. 5. Кривая время-скорость во время фазы подъема штанги от груди (исследуемый 4)

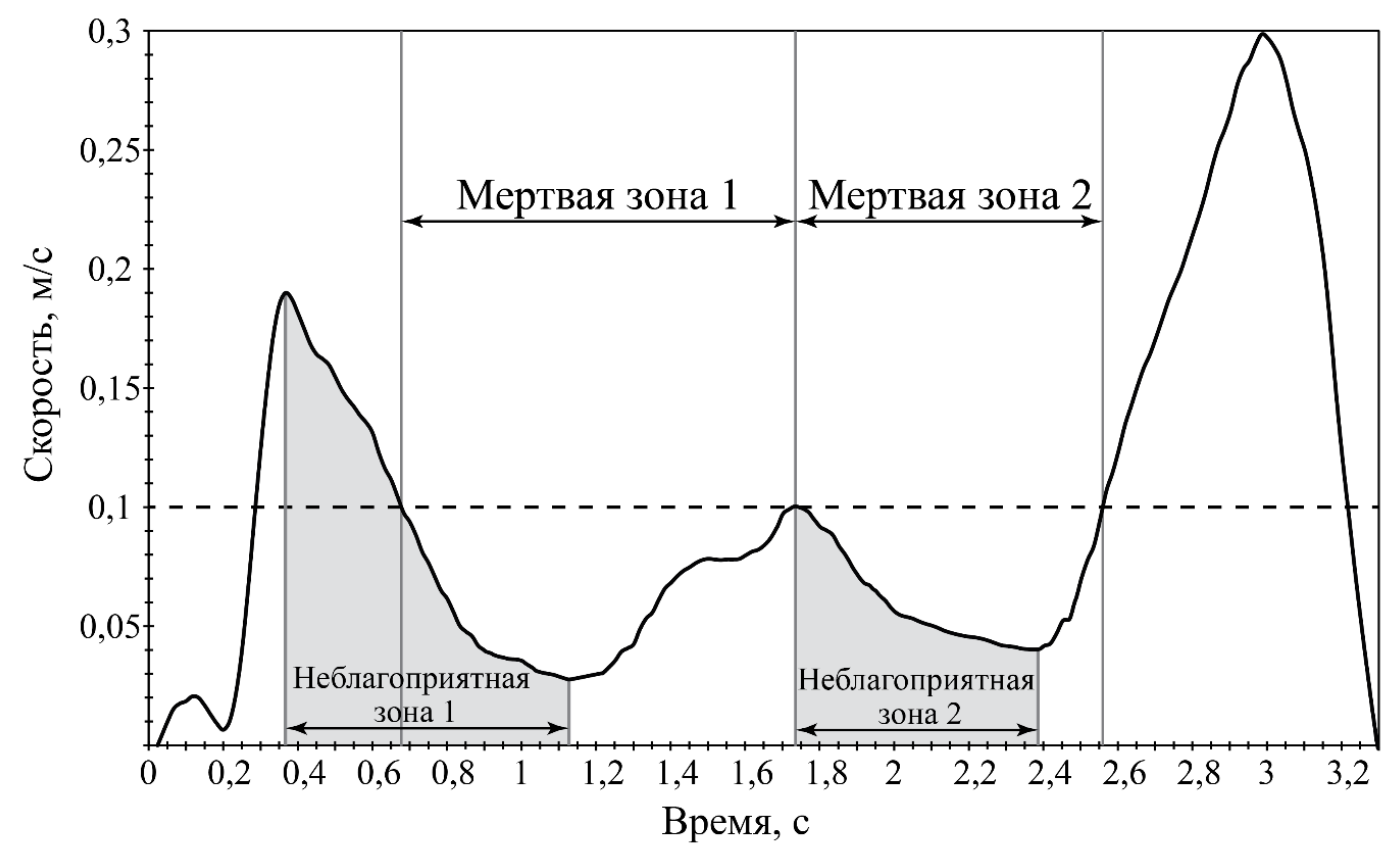

Рис. 6. Схема фазы подъема штанги от груди согласно введенным обозначениям

Для определения порогового уровня автор сравнил значения минимума скорости штанги $\left(v_{\min }\right)$ в фазе подъема штанги от груди у всех испытуемых. Среднее значение минимума вертикальной составляющей скорости штанги составило $(0,087 \pm 0,011) \mathrm{m} / \mathrm{c}$. Эти данные автор сопоставил с результатами, приведенными в литературе (таблица). 


\section{Кинематические характеристики жима штанги лежа в фазе подъема со $100 \%$-ным отягощением}

\begin{tabular}{|c|c|c|c|c|}
\hline Автор, год & $\begin{array}{c}\text { Количество } \\
\text { испытуемых }\end{array}$ & Испытуемые & $v_{\max 1}, \mathrm{M} / \mathrm{c}$ & $v_{\min }, \mathrm{M} / \mathrm{c}$ \\
\hline $\begin{array}{c}\text { C.С. Мартьянов, } \\
1991 \text { [2] }\end{array}$ & - & $\begin{array}{c}\text { І разряд - } \\
\text { мастер спорта }\end{array}$ & $0,25 \pm 0,02$ & $0,05 \pm 0,01$ \\
\hline $\begin{array}{c}\text { R. Van den Tillaar, } \\
\text { G. Ettema, 2010 [16] }\end{array}$ & 12 & Новички & $0,26 \pm 0,08$ & $0,07 \pm 0,05$ \\
\hline $\begin{array}{c}\text { B. Sheiko, B. Lukyanov, } \\
\text { V. Fetisov, 2010 [14] }\end{array}$ & 3 & $\begin{array}{c}\text { Мастер спорта, } \\
\text { мастер спорта } \\
\text { международного } \\
\text { класса, } \\
\text { заслуженный } \\
\text { мастер спорта }\end{array}$ & $0,17-0,28$ & - \\
\hline $\begin{array}{c}\text { H. Król, A. Golas, } \\
\text { G. Sobota, 2010 [10] }\end{array}$ & 16 & $\begin{array}{c}\text { Разная } \\
\text { квалификация }\end{array}$ & 0,20 & 0,15 \\
\hline
\end{tabular}

Как видно из таблицы, полученные авторами результаты в целом соответствуют данным других исследователей. Это позволило авторам определить диапазон значений скорости штанги, который тренеры гарантированно будут воспринимать как «мертвую зону». Диапазон скорости от 0 до 0,1 м/с воспринимался всеми тренерами как «мертвая зона».

\section{Критерий «мертвой зоны»}

Предлагаем считать «мертвой зоной» участок кривой время-скорость, в пределах которого значения вертикальной составляющей скорости штанги находятся ниже порогового уровня в 0,1 м/с. Критерием начала «мертвой зоны» является снижение вертикальной составляющей скорости штанги ниже $0,1 \mathrm{~m} / \mathrm{c}$, окончания - превышение порога вертикальной составляющей скорости штанги в $0,1 \mathrm{~m} / \mathrm{c}$.

Данное определение позволяет согласовать эмпирический опыт тренеров и судей, которые оценивают наличие «мертвой зоны» чисто визуально по скорости движения штанги, с результатами научных исследований.

Применение предложенного критерия к полученным нами экспериментальным данным свидетельствует о том, что в пяти случаях из десяти при выполнении удачной попытки с отягощением, составляющим $100 \%$ от максимума, наблюдалась одна «мертвая зона». Однако на кривой время - скорость она может проявляться в разные временные промежутки. «Мертвая зона» может проявиться либо в начале фазы подъема штанги от груди (см. рис. 2), либо в конце - перед завершением движения (см. рис. 3). В двух случаях из десяти автор зафиксировал наличие двух «мертвых зон»одной в начале подъема штанги и другой в конце подъема (см. рис. 4). Таким образом, можно утверждать, что в фазе подъема штанги возможно наличие двух «мертвых зон». В данном исследовании автор не сталкивался с ситуацией, когда в фазе подъеме штанги от груди проявлялось бы более двух «мертвых зон», хотя исключить такую вероятность не следует. В трех случаях из десяти (см. рис. 5), согласно разработанному нами критерию, «мертвая зона» отсутствовала. По-видимому, при определении значения максимального отягощения для данных спортсменов была допущена неточность. 
Таким образом, на основе предложенного нами подхода к выявлению «мертвой зоны» автор обнаружил три варианта изменения кривой время - скорость по критериям количества «мертвых зон» и периодов их возникновения.

1. Одна «мертвая зона» в начале фазы подъема штанги от груди (см. рис. 2).

2. Одна «мертвая зона» в конце фазы подъема штанги от груди (см. рис. 3).

3. Две «мертвые зоны»: первая проявляется в начале фазы подъема штанги от груди, а вторая - в конце данной фазы (см. рис. 4).

Для участка, на котором приложенная к штанге сила меньше веса штанги («мертвая зона» по J.E. Lander et al. [11]), автор предлагает ввести новый термин «неблагоприятная зона». По мнению автора, такой термин хорошо описывает изменения в механических условиях, с которыми сталкивается опорно-двигательный аппарат атлета в данный временной отрезок фазы подъема штанги от груди. Временные промежутки «неблагоприятной зоны» и «мертвой зоны» могут накладываться друг на друга, однако это наблюдается не всегда, например если «мертвая зона» отсутствует.

Разграничение понятий «неблагоприятная зона» и «мертвая зона» также позволяет объяснить результаты исследований [7] и [15], которые установили, что некоторые участники эксперимента терпели неудачу во второй части фазы подъема штанги от груди. Автор объясняет эти факты следующим. У этих исследуемых «мертвая зона» (по нашему критерию), т.е. снижение скорости штанги до нуля (так как штанга остановилась и спортсмен вынужден был прекратить попытку), проявилась во второй части фазы подъема штанги от груди. Вследствие этого попытка была неудачной. Однако так как авторы применяли прежние критерии определения «мертвой зоны», они указали, что неудача постигла спортсменов за пределами «мертвой зоны».

Анализ полученных нами экспериментальных данных позволил установить следующие закономерности:

1. При больших отягощениях всегда имеет место «неблагоприятная зона», однако не всегда есть «мертвая зона». Даже при использовании $100 \%$ отягощений скорость штанги может оставаться выше порогового значения 0,1 м/с (см. рис. 5).

2. События, происходящие в «неблагоприятной зоне», являются причиной возникновения «мертвой зоны».

3. Отказ от выполнения движения (неудачная попытка) всегда происходит в одной из «мертвых зон».

\section{ЗАКЛЮЧЕНИЕ}

1. До настоящего времени в научных и методических публикациях, посвященных жиму штанги лежа, понятие «мертвая зона» использовалось для описания двух разных явлений. В связи с этим автор предлагает разделить его на два понятия: «мертвая зона» и «неблагоприятная зона» - для более точного их описания и разграничения.

2. Критерием проявления «неблагоприятной зоны» является уменьшение вертикальной составляющей скорости штанги во время фазы подъема штанги от груди.

3. Критерием начала «мертвой зоны» является снижение вертикальной составляющей скорости штанги ниже 0,1 м/с, окончания - превышение порога вертикальной составляющей скорости штанги в $0,1 \mathrm{~m} / \mathrm{c}$.

4. Во время фазы подъема штанги от груди могут иметь место несколько «мертвых зон», каждой из которых обязательно предшествует своя «неблагоприятная зона».

5. Выявлены три базовых варианта кривой время-скорость по критериям количества и периодов возникновения «мертвых зон». В первом варианте имеется одна «мертвая зона» в начале фазы подъема штанги от груди; во втором варианте имеется 
одна «мертвая зона» в конце фазы подъема штанги от груди; в третьем варианте имеются две «мертвые зоны»: первая проявляется ближе к началу фазы подъема штанги, а вторая - ближе к окончанию данной фазы.

6. Введение нового критерия, описывающего понятие «мертвая зона», позволяет преодолеть противоречия в результатах исследований [7] и [15]. Согласно новому критерию, все неудачные попытки будут происходить в одной из «мертвых зон», так как при неудачной попытке скорость штанги снижается до нуля.

\section{СПИСОК ЛИТЕРАТУРЫ}

1. Манько И.Н. Биомеханические особенности проявления силы в пауэрлифтинге у квалифицированных спортсменов // Уч. записки ун-та им. П.Ф. Лесгафта. - 2008. - № 9 (43). C. $42-46$.

2. Мартьянов С.С. Анализ кинематики движения грифа штанги при выполнении жима лежа // Теория и практика физической культуры. - 1991. - № 1.- С. 38-40.

3. Самсонова А.В., Шейко Б.И., Кичайкина Н.Б., Самсонов Г.А. Механизм передачи импульса от ног к штанге при выполнении жима штанги лежа // Тр. каф. биомеханики ун-та им. П.Ф. Лесгафта. 2014. - Вып. 8.- С. 34-37.

4. Самсонова А.В., Шейко Б.И., Кичайкина Н.Б., Самсонов Г.А. Электрическая активность мышц нижних конечностей при выполнении жима штанги лежа // Уч. записки ун-та им. П.Ф. Лесгафта. 2014. - № 5 (111). - С. 159-165.

5. Шейко Б.И., Лукьянов Б.Г., Смольников Д.А., Фролов И.С., Фролов Г.С. Техника выполнения жима лежа // Железный мир. - 2007. - № 6. - С. 128-133.

6. Duffey M.J. A biomechanical analysis of the bench press: diss. of degree of doctor of philosophy. Pennsylvania, 2008. - $120 \mathrm{p}$.

7. Elliott B.C., Wilson G.J., Kerr G. A biomechanical analysis of the sticking region in the bench press // Medicine and Science in Sports and Exercise. - 1989. - Vol. 21, № 4. - P. 450-462. DOI: $10.1249 / 00005768-198908000-00018$

8. Gołaś A., Król H. Biomechanical analysis of flat bench pressing (case study) // Selected Problem of Biomechanics of Sport and Reabilitation. - Warsaw, 2014. - Vol. II. - P. 32-42.

9. Król H., Sobota G., Nawrat A., Wilk M. Complex analysis of movement in evaluation of flat bench press performance // XXIV International Symposium of Sport Biomechanics, 14-18 July 2006. - Salzburg, 2006. - P. 1-4.

10. Król H., Golas A., Sobota G. Complex analysis of movement in evaluation of flat bench press performance // Acta of bioengineering and biomechanics. - 2010. - Vol. 12, № 2. - P. 93-98.

11. Lander J.E., Bates B.T., Sawhill J.A., Hamill J. A comparison between free-weight and isokinetic bench pressing // Medicine and Science in Sports and Exercise. - 1985. - Vol. 17, № 3. - P. 344-353.

12. Madsen N., McLaughlin T. Kinematic factors influencing performance and injury risk in the bench press exercise // Medicine and Science in Sports and Exercise. - 1984. - Vol. 16, № 4. - P. 376-381. DOI: 10.1249/00005768-198408000-00010

13. Rippetoe M., Bradford S. Starting strength basic barbell training. - 3rd ed. - Wichita Falls: Aasggard Company, 2011. $-371 \mathrm{p}$.

14. Sheiko B., Lukyanov B., Fetisov V. What's the use of a bench press shirt for the athlete? // Powerlifting USA. - 2010. - № 3. - P. 12-13, 74-75.

15. Van den Tillaar R., Ettema G. A comparison of kinematics and muscle activity between successful and unsuccessful attempts in bench press // Medicine and Science in Sports and Exercise. - 2009. - Vol. 41, № 11. - P. 2056-2063. DOI: 10.1249/MSS.0b013e3181a8c360

16. Van den Tillaar R., Ettema G. The «sticking period» in bench press // Journal of Sports Sciences. - 2010. Vol. 28, № 5. - P. 529-535. DOI: 10.1080/02640411003628022

17. Van den Tillaar R., Saeterbakken A.H., Ettema G. Is the occurrence of the sticking region the result of diminishing potentiation in bench press? // Journal of Sports Sciences. - 2012. - Vol. 30, № 6. P. 591-599. DOI: 10.1080/02640414.2012.658844 


\section{DEFINING AND IDENTIFYING “THE STICKING PERIOD” IN A BENCH PRESS: A NEW APPROACH}

\section{G.A. Samsonov (Saint Petersburg, Russia)}

Horizontal bench press is a separate kind of sport and one of three competitive exercises in powerlifting. There is a distinctive time interval during the ascent phase called "the sticking period" when the bar velocity is reduced. There are differences in identifying "the sticking period" between coaches and researchers. Coaches tend to identify "the sticking period" empirically and subjectively, while researchers implement objective methods. Resulting disparity in comprehension of "the sticking period" between coaches and researchers impede the usage of the research data in the training process. The purpose of the study is to develop a new definition of "the sticking period" in a bench press and a new method of identifying it. Methods: filming in a sagittal plane and a computation of the bar velocity and acceleration using video data. Organization of the study: 10 skilled powerlifters performed the bench press with a 100\% load (1 repetition maximum) by powerlifting competition rules and without the equipment. 1 repetition maximum was determined by continuous increasing of the bar weight up to the fail attempt. The weight preceding the failed attempt was considered 1 repetition maximum. Results: "the sticking period" term has been split into two terms: "the sticking period" and "the disadvantageous period". "The sticking period" is the drop of the bar velocity below the threshold of $0.1 \mathrm{~m} / \mathrm{s}$, on reaching which the bar motion is considered too slow. "The disadvantageous period" is a part of the "time-force" curve during the ascent phase where the force applied to the bar is lesser then the bar weight. There may be two "sticking periods" - one at the beginning of the lift and another at the end. "The disadvantageous period" always precedes "the sticking period". Failed attempts always happen in "the sticking period".

Key words: bench press, powerlifting, "sticking point", "sticking period", "disadvantageous period". 